\title{
PULMONARY HYPERTENSION ASSOCIATED WITH NECROTIZING PULMONARY ARTERITIS
}

\author{
БY \\ J. D. AITCHISON AND H. G. RICHMOND \\ From the Royal Infirmary Aberdeen and the Department of Pathology, University of Aberdeen
}

Received November 22, 1954

Necrotizing arteritis limited to the pulmonary arteries has been described occasionally as a complication of mitral stenosis (Parker and Weiss, 1936), of Eisenmenger's complex (Old and Russell, 1947), and in patients dying with right heart failure of uncertain causation (McKeown, 1952). One such case in this last category, in which cardiac catheterization gave clear evidence of pulmonary hypertension, has recently come under our observation.

\section{CASE REPORT}

The patient, a boy of 13, was admitted to the Royal Infirmary, Aberdeen, in June, 1951, with chorea. He had previously suffered from measles, mumps, chicken pox and whooping cough. For a short time in 1949, and again in 1950, he had complained of mild pains in his thighs. Seven weeks before admission to hospital he developed a sore throat, followed in three weeks by severe pains in his legs. His doctor noted pyrexia and confined him to bed. After a fortnight, symptoms and signs of chorea appeared and a week later his right wrist became painful and swollen. Mild epistaxis occurred on two occasions.

Examination showed an intelligent, obese boy with frank chorea. There was a fading erythema on the upper trunk. Clinically, the heart was not enlarged. A soft systolic murmur was heard at the apex. The pulse rate was 100 and blood pressure 130/90. Hæmoglobin was $12 \cdot 4 \mathrm{~g}$. per $100 \mathrm{ml}$., white cell count 9,300 per c.mm., and E.S.R. $54 \mathrm{~mm}$. in one hour (Westergren). An electrocardiogram on 19/6/51 showed no definite abnormality (Fig. 1). But for the appearance of an erythematous rash, which, it was thought, might be due to sensitivity to phenobarbitone, the course of his illness was uneventful. The rash cleared up rapidly following treatment with " anthisan " (mepyramine maleate) $50 \mathrm{mg}$. b.d. The only abnormal finding when he left hospital on 30/7/51 was the apical systolic murmur.

This was noted again when he was seen as an out-patient in September, 1951. He returned to school then, three months after his admission to hospital. He remained well until February, 1952, when he developed what seemed to be an upper respiratory tract infection, followed by bronchitis. After this he became unduly breathless and tired on exertion. No cyanosis was observed. He was readmitted to hospital, because of these symptoms, in June, 1952. The only abnormal physical finding was the soft apical systolic murmur. The sedimentation rate was now $12 \mathrm{~mm}$. in one hour and the sleeping pulse 75-85. X-ray of the chest showed an increase in the transverse diameter of the heart (cardio-thoracic ration $0 \cdot 6: 1$ ) and prominence of the pulmonary artery segment. The branches of the pulmonary artery were, if anything, less obvious than normal. The electrocardiogram showed a gross change from the first tracing (Fig. 1). There was marked right axis deviation : in lead VI the $R$ wave measured $8 \mathrm{~mm}$. and the $S$ wave had disappeared. In lead aVR, R:S ratio was 4-5 and the T waves were inverted in leads II, III, aVF, VI, V3, and V5. The changes clearly indicated marked right ventricular hypertrophy and strain, which had developed within the previous year. He made no complaint while in the ward and was discharged home in August, 1952.

He was readmitted in November. After feeling vaguely unwell for three days, he had developed extreme breathlessness at rest, associated with a rigor and cyanosis. The dyspnœea passed off in about an hour but the cyanosis lasted somewhat longer. On admission two hours later, his colour was normal and he was free of symptoms. Physical examination showed a diffuse apex beat. Right ventricular pulsation 


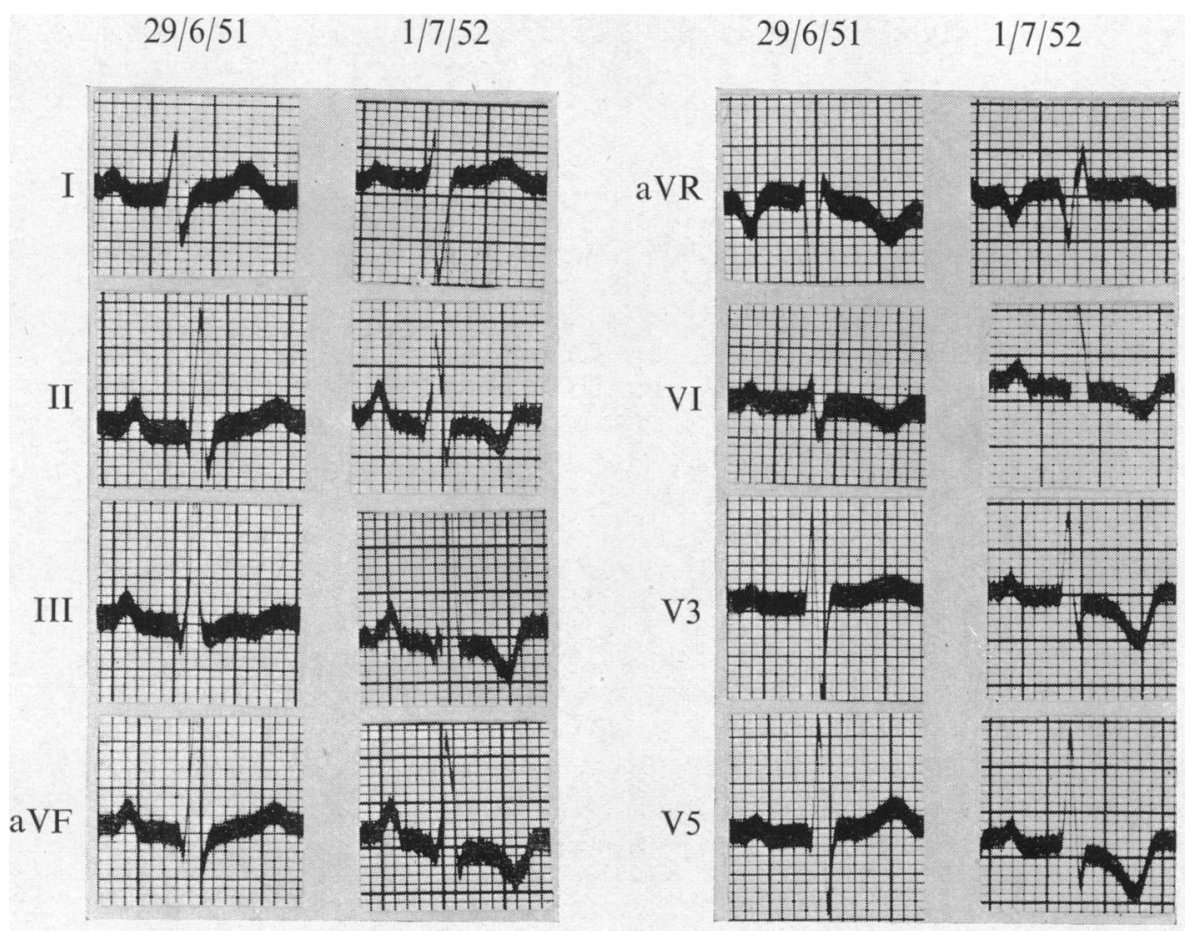

FIG. 1.-Electrocardiograms on $29 / 6 / 51$ and $1 / 7 / 52$, showing development of signs of right ventricular hypertrophy during this year.

could now be felt easily in the third and fourth intercostal spaces, and there was a diastolic thrill and murmur in the second and third interspaces, at the left sternal border. The systolic murmur was still present at the apex. The white cell count was 8600 per c.mm., E.S.R. $7 \mathrm{~mm}$. in one hour and Hb. $13.6 \mathrm{~g}$. per $100 \mathrm{ml}$. An electrocardiogram showed no significant change from that of July, 1952. The only new finding on X-ray screening of the heart was very vigorous pulsation in the enlarged pulmonary artery. There were no further developments while he was in the ward and he was discharged in December, 1952.

On January 2, 1953, he was readmitted for cardiac catheterization. The physical findings had not changed. E.S.R. was $2 \mathrm{~mm}$. in one hour; Hb. 14 g. per $100 \mathrm{ml}$. Cardiac catheterization was unusually difficult. Despite prolonged and repeated attempts the pulmonary artery could not be entered. The mean right ventricular pressure was grossly elevated $(60 \mathrm{~mm}$. $\mathrm{Hg}$ above a plane $5 \mathrm{~cm}$. behind the manubrium sterni; normal, approximately $10 \mathrm{~mm}$. $\mathrm{Hg}$ ). The right atrial pressure was $12 \mathrm{~mm}$. $\mathrm{Hg}$ (normal $5 \mathrm{~mm}$. $\mathrm{Hg}$ ). There was no significant variation in the oxygen content of samples of blood from the superior vena cava, the righ atrium and the right ventricle. Unfortunately an arterial sample was not obtained. Just after the catheterization was terminated the boy became cyanosed and his pulse rose to 130 . He lost consciousness momentarily on three occasions in quick succession. An electrocardiogram taken soon afterwards showed sinus tachycardia but no other new abnormality. He was drowsy throughout the remainder of the day but made no specific complaint and next day was back to his usual state. He went home on January 16. At this time there was clinical, cardiographic and radiological evidence of right ventricular hypertrophy. Pulmonary hypertension could be inferred from the findings on cardiac catheterization. The diastolic murmur was thought to be due to pulmonary incompetence.

On January 30, he was readmitted to the ward. During the previous few days he had become increasingly tired, weak and deeply cyanosed on the slightest exertion. He had vomited on several occasions. When he was seen in hospital varying cyanosis and signs of right ventricular failure were evident. There was no change in the cardiac murmurs. Despite treatment with digitalis and mercurial diuretics and the intermittent use of oxygen, he became steadily worse and died on February 4, 1953. Shortly before death the pulmonary diastolic murmur disappeared. 
Post-mortem Findings. Post-mortem examination showed hypertrophy and dilatation of the right heart and long-standing chronic venous congestion, evidenced by an advanced " nut-meg " condition of the liver, large pleural effusions and ascites.

The heart weighed $450 \mathrm{~g}$., compared with a normal weight of $216 \mathrm{~g}$. at this age (Vierordt, 1906). This increase in weight was almost wholly due to the great hypertrophy of the wall of the right ventricle, which was $10 \mathrm{~mm}$. across at its thickest part (normal $2 \cdot 5-3 \mathrm{~mm}$.). The trabeculæ and papillary muscles were very prominent, and there was a notable hypertrophy of the infundibulo-ventricular crest. There was no abnormality of the tricuspid or pulmonary valves. A few flecks of atheroma were evident in the pulmonary trunk. The left side of the heart was normal. The lungs were greatly collapsed. The trachea and main bronchi contained blood-stained muco-pus. A small infarct was noted at the base of the right upper lobe with recently formed thrombus in the related artery. No other macroscopic abnormality was noted. A search was made for thrombus formation in the systemic veins but none was found. The kidneys together weighed $280 \mathrm{~g}$. They were firm and congested. Stripping of the capsules left a smooth surface. The spleen and gastrointestinal tract showed notable congestion.

\section{Histological Report}

Heart. Foci of perivascular and subendocardial fibrosis were seen in the sections, associated with a sparse collection of mononuclear cells but nowhere was there a cellular aggregate identifiable as an Aschoff body, in three blocks taken from right and left ventricle.

Aorta and Pulmonary Trunk. There was no evidence of an aortitis or of arteritis in the main pulmonary trunk.

Kidneys. Many of the glomerular tufts were digitate and more cellular than normal, due to an increase in endothelial cells. Adhesions between tuft and Bowman's capsule were not infrequent. A very occasional sclerosed glomerulus could be identified. There were no notable changes in the tubules and renal vessels; in particular, there was no evidence of necrotizing arteritis or arteriolitis.

Lungs. Serial sections from nineteen blocks of tissue from different portions of lung were examined by hæmotoxylin and eosin, by Verhoeff's method for elastic tissue and by Masson's trichrome stain. In each section examined the great majority of the arterioles and small arteries showed some gross abnormality. In a small number of arteries an acute necrotizing lesion was seen. This varied from a zone of subendothelial fibrinoid necrosis to a lesion involving the whole wall, characterized by necrosis of the media and a heavy infiltration of all coats by neutrophil polymorphonuclear leucocytes and mononuclear cells (Fig 2 and 3); neither eosinophil leucocytes nor giant cells were identified. The majority of the vessels showed hypertrophy of the media and gross fibro-cellular thickening of the intima, without leucocytic infiltration. The lumen in these arteries was either greatly reduced or absent (Fig. 4). That this lesion could be remarkably localized is seen in a longitudinal section of artery in which a plaque of thickened intima on one segment of its wall almost occluded the lumen (Fig. 5). A number of extensively damaged arteries were observed, in which the processes of organization and recanalization were active (Fig. 6). Clumps of amorphous hyaline material were often seen in the walls of these recanalized vessels.

In addition to the arterial changes, an acute hæmorrhagic bronchitis was noted, accompanied by focal hæmorrhage and œdema in the related lung parenchyma.

\section{Comment on Pathological Findings}

Heart. The microscopical features were not diagnostic of a rheumatic lesion, but they are regarded as constituting evidence of an old myocarditis, which might well have been rheumatic.

The difficulty encountered in attempting to pass the cardiac catheter from the right ventricle into the pulmonary trunk may be explained by the hypertrophy of the infundibulo-ventricular crest which projected into the ventricular cavity.

Kidneys. The changes in the kidneys are not regarded as inflammatory in origin and are attributed mainly to the effects of prolonged and severe chronic venous congestion.

Lungs. The right ventricular hypertrophy, atheroma of the larger pulmonary arteries, and medial hypertrophy in the pulmonary arterial tree, are evidence of pulmonary hypertension. The possible significance of the necrotizing arteritis is discussed below. 


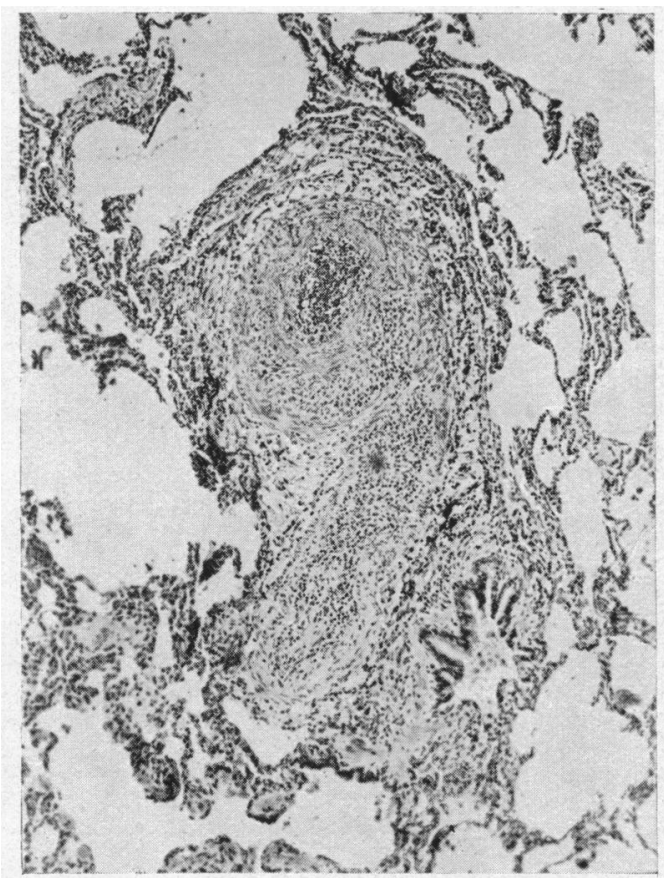

FIG. 2

Fig. 2.-Small pulmonary artery, showing medial necrosis and cellular infiltration of whole wall $(\times 70)$.

FIG. 3.-High-power view of Fig. 2, showing neutrophil polymorphonuclear leucocytes and mononuclear cells in the wall of the artery $(\times 280)$.

FIG. 4.-Pulmonary artery almost occluded by intimal thickening $(\times 70)$.

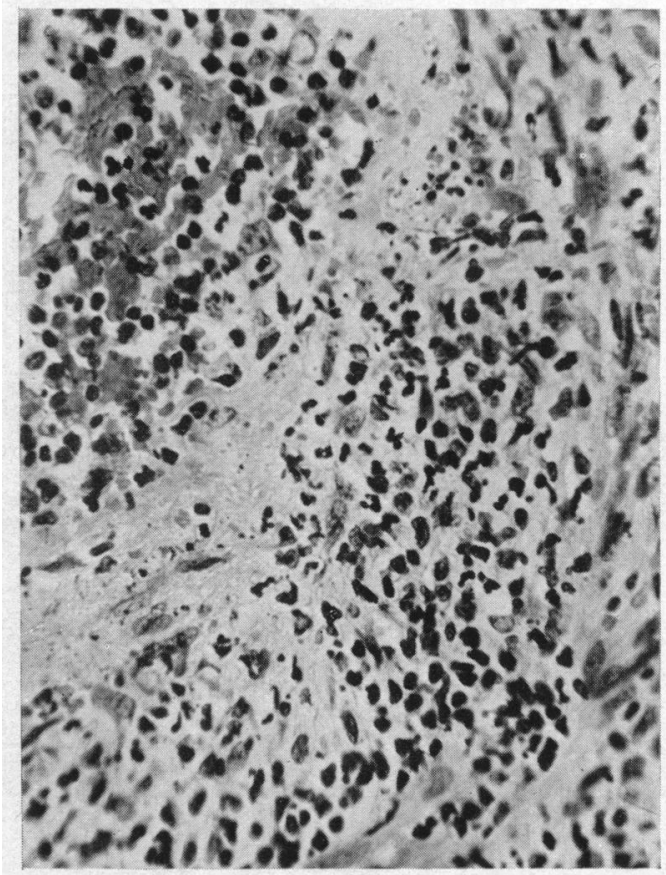

FIG. 3

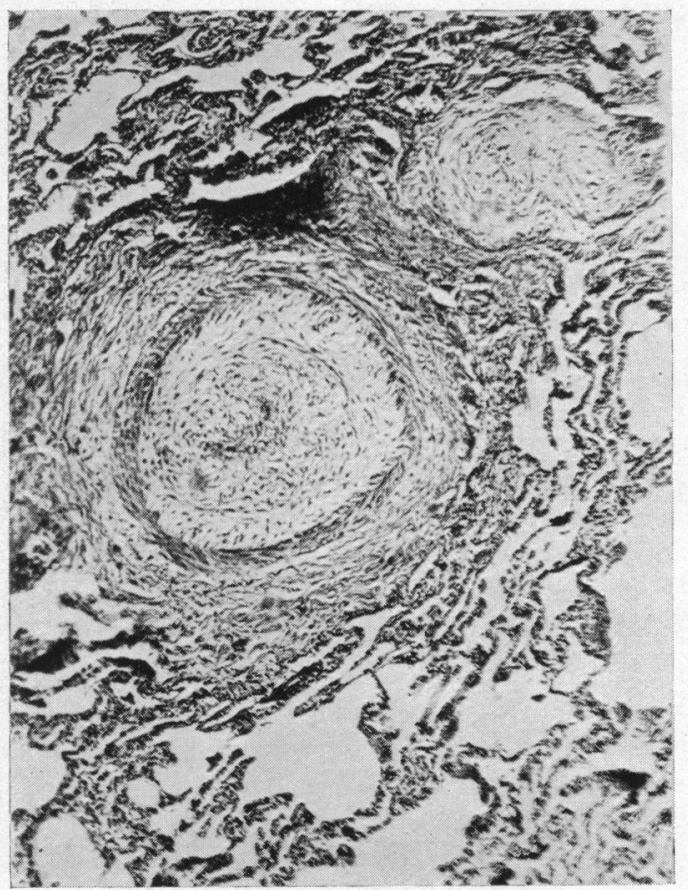

FIG 4 


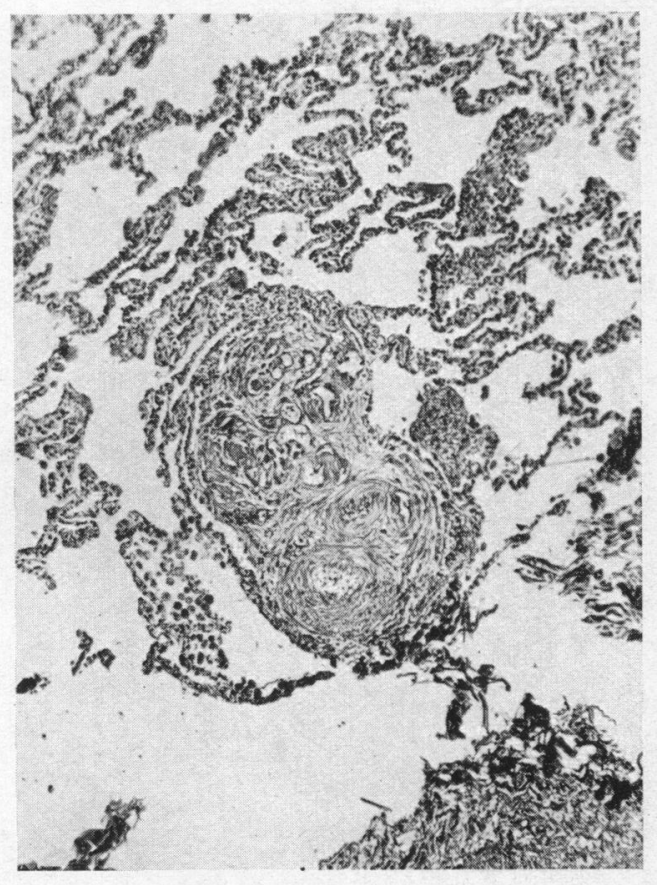

FIG. 5.-Pulmonary artery, showing localized focus of intimal fibrosis $(\times 90)$.

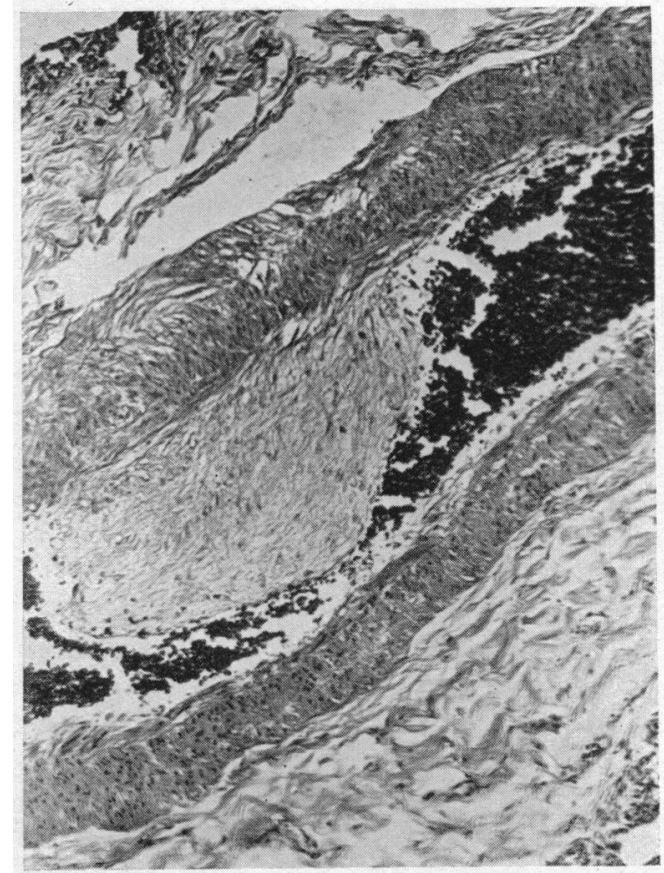

Fig. 6.-Recanalization of small pulmonary artery $(\times 70)$.

\section{Discussion}

Although direct measurement of the blood pressure in the pulmonary artery was not achieved in this case, the gross elevation of the mean pressure in the right ventricle, in the absence of any lesion such as pulmonary stenosis, leaves little or no doubt that there was considerable hypertension. Furthermore, the electrocardiographic evidence shows that right ventricular hypertrophy had been detectable more than seven months and less than nineteen months before death (Fig. 1). There was no mitral stenosis or congenital cardiac defect to account for the hypertension and hence the case must be considered either as one of idiopathic pulmonary hypertension with subsequent acute arterial changes or as hypertension secondary to necrotizing arteritis. The latter possibility will be considered first.

Primary Arterial Disease. It is well established that right ventricular hypertrophy and, by inference, pulmonary hypertension can be caused by an obliterative disease of the pulmonary arteries as in bilharzial disease of the lungs (Shaw and Ghareeb, 1938; Bedford et al., 1946) and in carcinomatosis associated with invasion and blockage of the vessels (Morgan, 1949). In our case, the diagnosis of rheumatic arteritis must be considered. The patient had a history of chorea, leg pains, and at least one swollen joint about 19 months before death. At necropsy there was no evidence of an endocarditis but there were the non-specific features of a healed myocarditis, which might have been rheumatic in origin. Against a diagnosis of primary rheumatic arteritis the following histological evidence can be adduced. (1) Most of the lesions in the pulmonary arteries are much more recent than the known period of right ventricular hypertrophy. (2) If the whole syndrome had been due to a smouldering rheumatic process in the pulmonary arteries, it would be most unusual, indeed, to find it confined to these vessels while no active lesions are demonstrable in heart, aorta, or pulmonary trunk (Gross, 1935). According to Friedberg (1949), cor pulmonale, secondary to rheumatic pulmonary arteritis, has never been proven. 
The lesions observed in the pulmonary arteries could be interpreted as polyarteritis nodosa or as a manifestation of allergy. That such a picture can result from allergy has been shown experimentally by Rich and Gregory (1943), who established in rabbits a condition similar to serum sickness in man. In this boy a rash developed during the exhibition of phenobarbitone at the time of his chorea, and some effect on his pulmonary arteries could be postulated. The recent character of most of the arterial lesions makes it unlikely that such a process initiated the pulmonary hypertension.

Idiopathic Pulmonary Hypertension. Idiopathic hypertension in the pulmonary arteries, evidenced by otherwise unexplained hypertrophy of the right ventricle, has been described when no significant structural changes could be demonstrated in the arteries (East, 1940; Armstrong, 1940). In at least one case (Whittenberg, 1950) pulmonary hypertension has been proved by cardiac catheterization, and subsequent post-mortem examination showed only minimal changes in the vessels. It has been estimated (Dresdale et al., 1951) that about half of the cases show occlusive lesions of the smaller arteries and arterioles.

Necrotizing pulmonary arteritis has been described in a case of idiopathic pulmonary hypertension (Symmers, 1952). McKeown (1952) described similar changes in four cases of right ventricular failure of unknown ætiology. It has been recorded in the pulmonary hypertension of Eisenmenger's complex (Old and Russell, 1947; Kipkie and Johnson, 1951). It has been found where pulmonary hypertension has occurred from mitral stenosis (Parker and Weiss, 1936; Symmers, 1952; Hicks, 1953). Conflicting conclusions have been drawn by these authors about the cause of the lesions Polyarteritis nodosa, hypersensitivity reaction, and rheumatism have all been suggested. Pulmonary hypertension seems to be the only factor common to the clinical conditions described, and Symmers' (1952) suggestion that the necrotizing arteritis is the result of pulmonary hypertension seems the best explanation. He compared the changes to those of systemic hypertension in its malignant phase.

In our case, right ventricular hypertrophy was well established seven months before death and therefore pulmonary hypertension must have been present for an even longer period. There is little doubt that the majority of the arterial changes were much more recent and accordingly we regard our case as one of idiopathic pulmonary hypertension with subsequent necrotizing arteritis. The arterial changes are of such severity and so widespread that they must, by obstructing the pulmonary arterial branches, have caused further increase in pulmonary artery pressure, so producing a vicious circle and what might be termed a "malignant " termination.

The cause of the initial rise in pulmonary artery pressure is unknown. Anoxia has been shown to cause pulmonary hypertension experimentally (von Euler and Liljestrand, 1946) and it is thought to be the main cause of cor pulmonale in chronic pulmonary emphysema (Harvey et al., 1951). It is worthy of note that cyanosis appeared late in the course of the illness, in our case, and that even three weeks before death there was no evidence of polycythæmia to suggest long standing arterial anoxia.

\section{SUMMARY}

A case of pulmonary hypertension and necrotizing pulmonary arteritis is described.

Serial electrocardiograms allowed some assessment of the rate of development of the hypertrophy of the right ventricle and, indirectly, of the pulmonary hypertension.

The relationship between the hypertension and arteritis is discussed, and the concept of a " malignant " ending to an idiopathic pulmonary hypertension is favoured.

Cardiac catheterization was unusually difficult to perform and was followed by syncopal attacks.

Cyanosis appeared late in the illness and there was no evidence of polycythæmia to suggest long standing arterial anoxia.

We are greatly indebted to Dr. R. J. Duthie for permission to publish this case, and to Professor J. S. Young and Dr. Duthie for helpful advice and criticism. We wish to thank Mr. R. Drummond for the photographs and Mr. N. Mowat for technical help. 


\section{REFERENCES}

Armstrong, T. G. (1940). Brit. Heart J., 2, 201.

Bedford, D. E., Aidaros, S. M., and Girgis, B. (1946). Brit. Heart J., 8, 87.

Dresdale, D. T., Schultz, M., and Michtom, R. J. (1951). Amer. J. Med., 11, 686.

East, T. (1940). Brit. Heart J., 2, 189.

von Euler, U. S., and Liljestrand, G. (1946). Act. physiol. Scand., 12, 301.

Friedberg, C. K. (1949. Diseases of the Heart. W. B. Saunders and Co., Philadelphia.

Gross, L. (1935). Amer. J. Pathol., 11, 631.

Harvey, R. M., Ferrer, M. I., Richards, D. W., and Cournand, A. (1951). Amer. J. Med., $10,719$.

Hicks, J. D. (1953). J. Path. Bact., 65, 333.

Kipkie, G. F., and Johnson, D. S. (1951). Arch. Path., 51, 387.

McKeown, F. (1952). Brit. Heart J., 14, 25.

Morgan, A. D. (1949). J. Path Bact., 61, 75.

Old, J. W., and Russell, W. O. (1947). Amer. J. Path., 23, 903.

Parker, F., and Weiss, S. (1936). Amer. J. Path., 12, 573.

Rich, A. R., and Gregory, J. E. (1943). Bull. Johns Hopkins Hosp., 72, 65.

Shaw, A. F. B., and Ghareeb, A. A. (1938). J. Path. Bact., 46, 401.

Symmers, W. St. C. (1952). J. Clin. Path., 5, 36.

Vierordt, H. (1906). Anatom. Daten. u. Tabellen. Verlag von Gustav Fischer, Jena.

Whittenberg, S. J. (1950). Cited by Dresdale et al. 